\title{
Physical disability and cognitive impairment among recipients of long-term care
}

\author{
Øystein Døhl *1,2, Helge Garåsen ${ }^{1,2}$, Jorid Kalseth ${ }^{3}$, Jon Magnussen ${ }^{1}$ \\ ${ }^{1}$ Department of Public Health and General Practice, Faculty of Medicine, Norwegian University of Science and Technology, \\ Trondheim, Norway \\ ${ }^{2}$ Department of Health and Welfare Services, City of Trondheim, Norway \\ ${ }^{3}$ Department of Health Research, SINTEF Technology and Society, Trondheim, Norway
}

Received: November 23, 2015

DOI: $10.5430 /$ jnep.v6n $7 \mathrm{p} 1$
Accepted: January 19, $2016 \quad$ Online Published: February 1, 2016

URL: http://dx.doi.org/10.5430/jnep.v6n7p1

\begin{abstract}
Background and objective: For practical policy purposes variables describing disability and impairment should be aggregated into broader factors. By using data from a Norwegian mandatory system the objective of this study was to analyse whether the number of factors describing the need for long-term care differs between recipients of home care and nursing home residents and according to the age or gender of long-term care recipients. The hierarchical order of the variables within each factor is determined to assess whether there are important informational gaps in the description of recipients.

Methods: Data are from a mandatory system characterizing all recipients of public long term care in Norway. Two groups of public care recipients were included: elderly (67 years and older) individuals receiving home care services $(\mathrm{N}=2,493)$ and patients in nursing homes $(\mathrm{N}=1,218)$. Exploratory factor analysis (EFA), Confirmatory factor analysis $(\mathrm{CFA})$ and item response analysis (IRT) were used to determine the number of factors and the hierarchical structures of the variables.

Results: Two factors were sufficient to characterise need for both nursing home residents and home dwelling elderly. This result is not sensitive to stratification by age and gender. IRT analysis revealed large informational gaps suggesting that the used instrument fails to sufficiently capture important aspects of user needs.

Conclusions: Factorization suggests that all elderly long term care users can be adequately described along two dimensions; on reflecting physical disability and one reflecting cognitive impairment. However, both the number of factors and the variable contained in each factor are likely to depend on the instrument used to characterise LTC users. Large informational gaps suggest a need to supplement the national information system used in Norway.
\end{abstract}

Key Words: Elder care, Nursing home care, Disability, Long term care

\section{INTRODUCTION}

Using data from a mandatory system used to characterize individual users of long term care in Norway (the IPLOSsystem), the objective of this article is to analyse whether the number of factors describing the need for long-term care differs between recipients of home care and nursing home residents. Furthermore whether there are differences between those aged 67-79 and those aged 80+, and also whether there are differences between men and women. Through this analysis we assess how variables describing physical disability and cognitive impairment can be grouped in broader factors for the purpose of financing and planning of long term care

\footnotetext{
*Correspondence: Øystein Døhl; Email: oystein.dohl@ntnu.no; Address: Department of Public Health and General Practice, Faculty of Medicine, Norwegian University of Science and Technology, Trondheim, Norway.
} 
services. Finally we discuss the IPLOS system in terms of how well it describes the full spectrum of the variables that are important in the assessment of user needs.

Both disability and cognitive impairment have consistently been found to be strong predictors of the use of long-term care services. ${ }^{[1-5]}$ Although the scores on a variety of separate variables are important for individual assessment and follow-up, some form of aggregation/grouping of variables is convenient if this information is to be used for planning purposes, financing or population-based resource allocation. This raises the question of how disability and impairment variables can be grouped together and also how many separate factors that are needed to sufficiently capture needs. What is also important, from a policy perspective, is whether the grouping of variables and the number of factors differ between different types of users.

Disability is commonly evaluated according to a range of functional capabilities, e.g., activities of daily living (ADL), mobility and instrumental activities of daily living (IADL). Indeed, many of the available instruments use ADL/IADL variables to describe disability, most built on the works of Katz, Lawton and Barthel. ${ }^{[6-8]}$ Cognitive impairment can be evaluated according to, e.g., the Mini Mental State Examination (MME), the Cognitive Performance Scale (CPS) and diagnoses. ${ }^{[9,10]}$ Some instruments also include variables that capture both disability and cognitive impairment, e.g., The Functional Independence Measure (FIM), The Functional Autonomy Measurement System (SMAF) and The Activity Measure for Post-Acute Care (AM-PAC). ${ }^{[1-14]}$

There is a large literature that analyses how ADL, mobility and IADL variables can be aggregated into broader factors. The literature, however, is largely inconclusive, suggesting they may be grouped in from one to three unique factors. ${ }^{[15-17]}$ One explanation for the conflicting results may be differences in the underlying set of variables that describe disability or cognitive impairment. Whereas ADL variables describe basic self-care activities and mobility, the IADL variable sub-domains are often less precisely defined. ${ }^{[18,19]}$ Moreover, some instruments include variables that describe social factors and/or cognitive impairment under the IADL heading, and thus, the reason for not combining ADL and IADL into one common factor could be because the latter can include social ${ }^{[20,21]}$ or cognitive variables. ${ }^{[14,17,22-25]}$

The number of factors needed to describe needs may also vary between different types of users, depending on setting (home care vs. nursing home), age or gender. Again, the literature provides conflicting results on this topic. ${ }^{[13,15,21,26,27]}$

In practical use, there will be a trade-off between an in- strument that includes multiple variables and covers a wide spectrum of needs and a more parsimonious instrument that reduces the administrative burden. ${ }^{[19]}$ Measures of ADL, mobility, IADL and cognitive impairment have been shown to vary in their ability to detect disability. ${ }^{[13,16,28-30]}$ Thus, important variables may be missing in the instruments that are used ("gaps"), and the aggregated factors may consequently be less precise.

In Norway, the provision of public long-term care is decentralised to 428 municipalities. Since 2006 municipalities have been required to assess user needs using a standardised national registration system (IPLOS) that contains 15 variables describing physical disability and cognitive impairment. ${ }^{[31]}$ While the primary purpose with IPLOS was to provide local and central authorities with information about long term care use and long term care users, the potential for using the system for financial purposes was also considered. Intentionally the idea was to link IPLOS to the Resident Assessment Instrument (RAI) and the Resource Utilization Groups system (RUG). ${ }^{[32-34]}$ In the final version, however, the selected ADL variables had clear similarities with those used by Katz, Lawton and Barthel. ${ }^{[6-8]}$ Characterisation of disability in IPLOS is based on the principles described by the World Health Organization's (WHO) classification of disabilities. ${ }^{[35]}$ The IPLOS system is unique for Norway, the most similar system is the Canadian SMAF. ${ }^{[12]}$ While IPLOS is now an established tool in the assessment of individual user need, ${ }^{[36]}$ it is still rarely used by municipalities in aggregate planning, monitoring or financing of services.

\section{METHODS}

The data obtained covered all recipients of long term care aged 67 years or older in the municipality of Trondheim. The first group comprised 2,493 persons who received public home care (home-dwelling elderly). The second group consisted of 1,218 elderly who received long-term care in nursing homes $(1,152$ persons) or sheltered housing units (64 persons). Together, these two groups constitute approximately $18 \%$ of the elderly aged 67 years or older who lived in Trondheim at the time of the study. A quantitative crosssectional design was used.

Data were collected during a four-week period in October 2012. Data are routinely registered for all individuals who receive public nursing home or home care services. We utilised the 15 variables (see Table 1) that described disabilities related to ADL (variables 1-4), mobility (variables 5-6), IADL (variables 7-9), and cognitive and behavioural impairment (variables 11-15). Variable 10, "maintaining one's own health", is similar to Lawton and Brody's original IADL variable "responsibility for own medications", [7] 
but it has a broader definition. It is not clear whether this expanded variable should be interpreted as an IADL or a cognitive variable. The 15 variables were scored using a five-point scale. Higher scores imply lower capability and scores of three or higher indicate the need for assistance. A score of one indicates no need for help, and a score of two indicates that the person is capable of performing the task but with difficulties. Scores are updated whenever the recipient's condition changes. The data contained no missing values. All personnel who registered the data had been licensed and trained by the municipality's authorisation program. ${ }^{[37]}$ All recipients were scored according to their potential capacity to perform the tasks described in each variable.

\section{Data analyses}

Data were analysed using the following procedure. The datasets were randomly divided into two halves. First, the number of factors was established using exploratory factor analysis (EFA) on one half of the datasets. ${ }^{[38]}$ Because data were ordinal, polychoric rather than Pearson correlation was used. ${ }^{[39]}$ The number of factors to retain was determined based on combining the Kaizer criteria, a parallel analysis and a scree plot. ${ }^{[40]}$ The parallel analyses were conducted with 50 randomisations. Variables were grouped into one factor if their factor loading was higher than $0.40 .{ }^{[40]}$ Internal consistency was tested with Cronbach's alpha and was computed for each factor, based on the factors for which the variables showed the highest loading. Cronbach's alpha values above 0.70 were interpreted as good, and values above 0.90 were considered very good. ${ }^{[41]}$

Secondly the factorisations from the step 1 were tested by use of confirmatory factor analysis (CFA) on the other half of the sample. We used a Root Mean Square Error of Approximation (RMSEA) to test the covariance of the model against the covariance of the sample. As a measure of the residual correlation we used Standardized Root Mean Square Residual (SRMR). Chi squared tests which is often used could be inflated by high sample size, and a Comparative fit index (CFI) is considered as more prober for large samples. ${ }^{[40,42]}$ CFI was used to compare the model with a more restrictive model assuming no covariance among the variables. ${ }^{[40,43,44]}$ RMSEA should be as low as possible preferable below 0.06 and the upper $90 \%$ confidence interval should be 0.10 or below. SRMR should be as low as possible preferable 0.10 or below and the CFI should be close to 0.90 or higher. ${ }^{[16,40]}$ We used both a maximum likelihood and quasi-maximum likelihood with robust standard errors procedure to correct for the effect of nonlinearity of the standard errors. The two methods produced nearly the same values. The results from the maximum likelihood are presented.
To determine the hierarchical order of the variables, we used item response theory (IRT). IRT analysis requires a dichotomy in the responses; thus, all recipients of care were categorised as either disabled (score 3 to 5) or non-disabled (score 1 or 2 ) for each variable. Both one-parameter logistic (1PL) and two-parameter logistic (2PL) IRT models were estimated. Our main interest was the parameter that describes variable (or item) difficulty, $\beta$ (see Tables 2 and 3 ). This parameter measures, in standard deviations, the distance from the overall mean score (standardised) on the latent variable $\theta$ (disability/impairment) when the probabilities of scoring "need for help" (score 3-5) or "no need for help" (score 1-2) are equal (i.e., 50\%). ${ }^{[45,46]}$ Thus, higher $\beta$ values are associated with more difficult tasks (variables). There are no clear guidelines for the recommended size of the gaps between items, although some reports have suggested values between 0.15 and $0.30 .^{[30,47,48]}$

The analyses were performed with SPSS version 21. IBM Corp. Armonk, NY. and Stata 13.1 StataCorp. College Station, TX.

The study was approved by the Regional Committee for Medical and Health Research Ethics (REK) and the Ombudsman for Research at the Norwegian Social Science Data Services (NSD).

\section{RESULTS}

\subsection{Descriptive statistics}

About $2 / 3$ of elderly receiving home care and nearly $3 / 4$ of elderly in nursing home were female (see Table 4 ). The average score of all 15 variables were 2.1 for home dwelling elderly and 3.5 for those living in nursing home.

The average score for each of the 15 disability/impairment variables was generally higher (indicating greater needs) for the elderly in nursing homes than for the home-dwelling elderly.

\subsection{Dimensionality}

Table 1 shows that the data were non-normal; thus, the use of polychoric correlation based on maximum likelihood may lead to biased estimates. Still, polychoric correlation is often preferred for ordinal data. ${ }^{[49]}$ Because of the correlations between the factors, an oblique rotation was used in the EFA (direct oblim with $\delta=0) .{ }^{[50,51]}$ Estimated factor loadings are shown in Tables 5-7.

The EFA indicated that the 15 variables could be grouped into two factors for both the home-dwelling elderly and the elderly who lived in nursing homes. For both groups, the eigenvalue for a third factor was below Kaizer's eigenvalue criteria, at 0.34 and 0.67 , respectively. A two-factor model 
was supported by both the parallel analysis and the scree plots (not presented here). For both groups, the first factor consisted of disability variables (ADL, mobility and IADL) and the second of cognitive and behavioural variables. For the elderly individuals who lived at home, the variable "shopping" demonstrated loadings above the threshold of 0.40 on both factors, it also had high loadings on both factors for those who lived in nursing homes. The results from the EFA analysis for home dwelling elderly and nursing home residents related to age and gender is in Tables 6 and 7. Due to small sample sizes it was not possible to do an age-group or gender-specific CFA on the nursing home residents. However for the home dwelling elderly results were nearly identical for the two age groups as well as for men and women. These results are shown in Table 3.

Table 1. Characteristics of the study sample, share of recipient who score 1 and 2 and share of recipient who score 3, 4 and 5 ,with the average score and $95 \%$ confidence interval (C.I.). Home care $(\mathrm{N}=2,493)$ and nursing home residents $(\mathrm{N}=1,218)$

\begin{tabular}{|c|c|c|c|c|c|c|}
\hline & \multicolumn{3}{|c|}{ Home-dwelling elderly } & \multicolumn{3}{|c|}{ Nursing home residents } \\
\hline & Score 1-2 & Score 3-5 & Mean score (C.I.) & Score 1-2 & Score 3-5 & Mean score (C.I.) \\
\hline 1 Eating & $96 \%$ & $4 \%$ & $1.16(1.14-1.18)$ & $62 \%$ & $38 \%$ & $2.12(2.05-2.19)$ \\
\hline 2 Dressing & $61 \%$ & $39 \%$ & $2.01(1.96-2.05)$ & $11 \%$ & $89 \%$ & $3.72(3.66-3.78)$ \\
\hline 3 Personal hygiene & $40 \%$ & $60 \%$ & $2.44(2.40-2.48)$ & $2 \%$ & $98 \%$ & $4.00(3.95-4.05)$ \\
\hline 4 Using the toilet & $81 \%$ & $19 \%$ & 1.61 (1.57-1.65) & $25 \%$ & $75 \%$ & $3.36(3.29-3.44)$ \\
\hline 5 Indoor mobility & $83 \%$ & $17 \%$ & 1.87 (1.83-1.90) & $37 \%$ & $63 \%$ & 3.07 (2.99-3.15) \\
\hline 6 Outdoor mobility & $51 \%$ & $49 \%$ & $2.55(2.51-2.60)$ & $10 \%$ & $90 \%$ & 4.03 (3.97-4.09) \\
\hline 7 Cooking & $51 \%$ & $49 \%$ & $2.33(2.28-2.38)$ & $1 \%$ & $99 \%$ & $4.50(4.46-4.55)$ \\
\hline 8 Shopping & $29 \%$ & $71 \%$ & $2.82(2.78-2.87)$ & $1 \%$ & $99 \%$ & 4.53 (4.49-4.57) \\
\hline 9 House keeping & $11 \%$ & $89 \%$ & $3.40(3.37-3.44)$ & $0 \%$ & $100 \%$ & $4.72(4.68-4.75)$ \\
\hline 10 Maintaining own health & $15 \%$ & $85 \%$ & $2.93(2.90-2.96)$ & $1 \%$ & $99 \%$ & $4.24(4.20-4.28)$ \\
\hline 11 Communication & $94 \%$ & $6 \%$ & $1.23(1.20-1.25)$ & $54 \%$ & $46 \%$ & $2.41(2.34-2.47)$ \\
\hline 12 Social interaction & $67 \%$ & $33 \%$ & $1.84(1.81-1.88)$ & $19 \%$ & $81 \%$ & $3.13(3.08-3.19)$ \\
\hline 13 Daily decision making & $74 \%$ & $26 \%$ & $1.76(1.72-1.80)$ & $9 \%$ & $91 \%$ & 3.77 (3.72-3.83) \\
\hline 14 Memory & $77 \%$ & $23 \%$ & $1.74(1.70-1.77)$ & $17 \%$ & $83 \%$ & $3.43(3.37-3.49)$ \\
\hline 15 Behavioural control & $96 \%$ & $4 \%$ & $1.14(1.13-1.16)$ & $58 \%$ & $42 \%$ & $2.20(2.13-2.27)$ \\
\hline
\end{tabular}

Table 2. Confirmatory factor analysis on one half of the sample of home dwelling elderly and nursing home residents

\begin{tabular}{|c|c|c|}
\hline & $\begin{array}{l}\text { Home dwelling } \\
\text { elderly }\end{array}$ & $\begin{array}{l}\text { Nursing homes } \\
\text { patients }\end{array}$ \\
\hline \multicolumn{3}{|l|}{ Fit statistics } \\
\hline RMSEA & $0.09(0.08-0.09)^{*}$ & $0.14(0.13-0.15)^{*}$ \\
\hline CFI & 0.83 & 0.81 \\
\hline SRMR & 0.06 & 0.10 \\
\hline Covariance & 1 & 2 \\
\hline 1 & 1 & 1 \\
\hline 2 & 0.56 & 0.59 \\
\hline
\end{tabular}

$* 90 \%$ confidence interval

Cronbach's alpha values were between 0.79 and 0.94 , thus all but one was well above the recommended level of 0.70 .

The results from the CFA analysis partly confirmed the results from the EFA analysis. For the home dwelling elderly both the RMSEA and SRMR results supported the two factor model. For the nursing-home residents the CFA results did not clearly support the two factor model from the EFA analyses. However, the covariance between the two factors was 0.59, and a CFA testing whether a composite (one-factor) model gave an even poorer fit (results not shown).

\subsection{Hierarchical ordering of the variables and gaps}

IRT analysis was conducted separately for each of the factors. Because the differences between the 1PL and 2PL models were negligible, only the 1PL results are presented (see Table $8)$.

For both groups of elderly, "housekeeping" was found to be the most difficult disability task, whereas "eating" was the least difficult. For the cognitive variables, "maintaining own health" was the most difficult, whereas "behavioural control" was the least difficult task. Generally, all variables were relatively more difficult for those who lived in nursing homes than for the home-dwelling elderly. 
Table 3. Confirmatory factor analysis of home dwelling elderly, according to gender and age

\begin{tabular}{|c|c|c|c|c|c|c|c|c|}
\hline & \multicolumn{2}{|c|}{ Female } & \multicolumn{2}{|c|}{ Male } & \multicolumn{2}{|l|}{$67-79$} & \multicolumn{2}{|l|}{$80+$} \\
\hline RMSEA & \multicolumn{2}{|c|}{$0.10(0.09-0.10)^{*}$} & \multicolumn{2}{|c|}{$0.12(0.11-0.12)^{*}$} & \multicolumn{2}{|c|}{$0.12(0.11-0.12)^{*}$} & \multicolumn{2}{|c|}{$0.09(0.09-0.10)^{*}$} \\
\hline CFI & \multicolumn{2}{|l|}{0.88} & \multicolumn{2}{|l|}{0.86} & \multicolumn{2}{|l|}{0.86} & \multicolumn{2}{|l|}{0.89} \\
\hline SRMR & \multicolumn{2}{|l|}{0.07} & \multicolumn{2}{|l|}{0.07} & \multicolumn{2}{|l|}{0.07} & \multicolumn{2}{|l|}{0.06} \\
\hline Covariance & 1 & 2 & 1 & 2 & 1 & 2 & 1 & 2 \\
\hline 1 & \multicolumn{2}{|l|}{1} & \multicolumn{2}{|l|}{1} & \multicolumn{2}{|l|}{1} & \multicolumn{2}{|l|}{1} \\
\hline 2 & 0.58 & 1 & 0.66 & 1 & 0.61 & 1 & 0.58 & 1 \\
\hline
\end{tabular}

Table 4. Descriptive statistics of recipients

\begin{tabular}{lll}
\hline & $\begin{array}{l}\text { Home dwelling } \\
\mathbf{( N = 2 , 4 9 3 )}\end{array}$ & $\begin{array}{l}\text { Nursing homes } \\
\mathbf{( N = 1 , 2 1 8 )}\end{array}$ \\
\hline Percentage Men & $34 \%$ & $27 \%$ \\
Percentage age 67-79 & $28 \%$ & $22 \% *$ \\
Average score 15 items & 2.1 & 3.5 \\
Men & 2.1 & 3.5 \\
Women & 2.0 & 3.6 \\
67-79 & 2.1 & 3.6 \\
$80+$ & 2.0 & 3.5 \\
\hline
\end{tabular}

*Some recipients in nursing homes might be below 67 years old

Large differences between the item difficulty parameters $(\beta)$ identified areas in which the IPLOS instrument could be said to lack precision. For the home-dwelling elderly, there were larger gaps than recommended at both ends of the disability scale. For patients in nursing homes, there were smaller gaps between the most difficult variables but larger gaps between the moderately difficult variables.

\section{Discussion}

Grouping users of long-term care according to their needs is useful for policy makers for planning, financing and monitoring purposes. With a variety of available instruments that describe disability and cognitive impairments the literature is inconclusive as for how such a grouping should be done. Our analyses are based on the Norwegian IPLOS system, but the challenges in long term care facing policy makers are similar in other countries, thus we believe that our comparison of recipients of home care and nursing home provide insight beyond a specific Norwegian setting.

Table 5. EFA results-Eigenvalues, factor loadingsa from the pattern matrix and Cronbach's alpha values from home-dwelling elderly and nursing home residents

\begin{tabular}{|c|c|c|c|c|}
\hline \multirow{2}{*}{ Factors } & \multicolumn{2}{|c|}{ Home-dwelling elderly } & \multicolumn{2}{|c|}{ Nursing home residents } \\
\hline & 1 & 2 & 1 & 2 \\
\hline Eigenvalues & 8.08 & 1.70 & 8.06 & 1.91 \\
\hline Eigenvalues from parallel analysis & 1.13 & 1.10 & 1.19 & 1.15 \\
\hline 1 Eating & 0.48 & 0.32 & 0.54 & 0.33 \\
\hline 2 Dressing & 0.82 & 0.09 & 0.86 & 0.11 \\
\hline 3 Personal hygiene & 0.76 & 0.18 & 0.70 & 0.32 \\
\hline 4 Using the toilet & 0.81 & 0.06 & 0.83 & 0.10 \\
\hline 5 Indoor mobility & 0.96 & -0.24 & 0.95 & -0.24 \\
\hline 6 Outdoor mobility & 0.90 & -0.11 & 0.91 & -0.14 \\
\hline 7 Cooking & 0.64 & 0.34 & 0.60 & 0.34 \\
\hline 8 Housekeeping & 0.72 & 0.17 & 0.71 & 0.17 \\
\hline 9 Shopping & 0.56 & 0.42 & 0.37 & 0.54 \\
\hline 10 Maintaining own health & 0.18 & 0.67 & 0.19 & 0.72 \\
\hline 11 Communication & 0.18 & 0.59 & 0.15 & 0.65 \\
\hline 12 Social interaction & 0.20 & 0.60 & 0.19 & 0.61 \\
\hline 13 Daily decision taking & -0.01 & 0.91 & 0.02 & 0.88 \\
\hline 14 Memory & -0.12 & 0.86 & -0.16 & 0.86 \\
\hline 15 Behavioural control & 0.05 & 0.63 & -0.11 & 0.66 \\
\hline Cronbach’s alpha† & 0.91 & 0.79 & 0.90 & 0.85 \\
\hline
\end{tabular}

* Loadings > 0.40 are marked with boldface; † The Cronbach's alpha was computed within each factor based on the boldface variables. 
Table 6. EFA results-Eigenvalues, factor loadingsa from the pattern matrix values from home-dwelling elderly, above and below 80 years old, female and male

\begin{tabular}{|c|c|c|c|c|c|c|c|c|}
\hline \multirow{2}{*}{ Factors } & \multicolumn{2}{|l|}{$67-79$} & \multicolumn{2}{|l|}{$80+$} & \multicolumn{2}{|c|}{ Female } & \multicolumn{2}{|l|}{ Male } \\
\hline & 1 & 2 & 1 & 2 & 1 & 2 & 1 & 2 \\
\hline Eigenvalues & 8.58 & 1.86 & 7.86 & 1.64 & 7.86 & 1.75 & 8.55 & 1.70 \\
\hline 1 Eating & 0.49 & 0.34 & 0.47 & 0.29 & 0.44 & 0.34 & 0.55 & 0.30 \\
\hline 2 Dressing & 0.83 & 0.13 & 0.82 & 0.06 & 0.84 & 0.03 & 0.79 & 0.17 \\
\hline 3 Personal hygiene & 0.77 & 0.22 & 0.76 & 0.15 & 0.77 & 0.14 & 0.74 & 0.24 \\
\hline 4 Using the toilet & 0.86 & 0.04 & 0.79 & 0.05 & 0.83 & 0.02 & 0.79 & 0.09 \\
\hline 5 Indoor mobility & 1.00 & -0.21 & 0.93 & -0.25 & 0.94 & -0.23 & 1.00 & -0.24 \\
\hline 6 Outdoor mobility & 0.96 & -0.16 & 0.87 & -0.08 & 0.87 & -0.07 & 0.95 & -0.14 \\
\hline 7 Cooking & 0.66 & 0.35 & 0.64 & 0.32 & 0.67 & 0.31 & 0.61 & 0.37 \\
\hline 8 Housekeeping & 0.74 & 0.18 & 0.72 & 0.15 & 0.75 & 0.12 & 0.69 & 0.22 \\
\hline 9 Shopping & 0.57 & 0.42 & 0.56 & 0.42 & 0.54 & 0.42 & 0.57 & 0.44 \\
\hline 10 Maintaining own health & 0.12 & 0.71 & 0.23 & 0.64 & 0.18 & 0.67 & 0.20 & 0.66 \\
\hline 11 Communication & 0.22 & 0.60 & 0.17 & 0.58 & 0.15 & 0.61 & 0.24 & 0.54 \\
\hline 12 Social interaction & 0.19 & 0.65 & 0.21 & 0.57 & 0.22 & 0.55 & 0.16 & 0.70 \\
\hline 13 Daily decision taking & -0.03 & 0.95 & 0.02 & 0.89 & -0.02 & 0.92 & 0.02 & 0.90 \\
\hline 14 Memory & -0.11 & 0.83 & -0.13 & 0.90 & -0.11 & 0.87 & -0.13 & 0.84 \\
\hline 15 Behavioural control & 0.02 & 0.68 & 0.07 & 0.60 & 0.09 & 0.58 & -0.02 & 0.71 \\
\hline
\end{tabular}

* Loadings $>0.40$ are marked with boldface

Table 7. EFA results-Eigenvalues, factor loadingsa from the pattern matrix values from nursing home residents, above and below 80 years old, female and male

\begin{tabular}{|c|c|c|c|c|c|c|c|c|}
\hline \multirow{2}{*}{ Factors } & \multicolumn{2}{|l|}{$67-79$} & \multicolumn{2}{|l|}{$80+$} & \multicolumn{2}{|c|}{ Female } & \multicolumn{2}{|l|}{ Male } \\
\hline & 1 & 2 & 1 & 2 & 1 & 2 & 1 & 2 \\
\hline Eigenvalues & 8.31 & 2.17 & 10.42 & 1.25 & 7.99 & 1.94 & 8.12 & 1.86 \\
\hline 1 Eating & 0.61 & 0.32 & 0.39 & 0.50 & 0.55 & 0.35 & 0.52 & 0.28 \\
\hline 2 Dressing & 0.84 & 0.15 & 0.22 & 0.77 & 0.87 & 0.09 & 0.82 & 0.17 \\
\hline 3 Personal hygiene & 0.73 & 0.34 & 0.40 & 0.61 & 0.72 & 0.29 & 0.63 & 0.42 \\
\hline 4 Using the toilet & 0.86 & 0.09 & 0.22 & 0.76 & 0.83 & 0.10 & 0.82 & 0.12 \\
\hline 5 Indoor mobility & 1.03 & -0.30 & -0.21 & 1.00 & 0.94 & -0.23 & 0.97 & -0.26 \\
\hline 6 Outdoor mobility & 0.93 & -0.11 & -0.01 & 0.89 & 0.91 & -0.16 & 0.90 & -0.08 \\
\hline 7 Cooking & 0.66 & 0.35 & 0.54 & 0.47 & 0.63 & 0.31 & 0.54 & 0.43 \\
\hline 8 Housekeeping & 0.77 & 0.13 & 0.44 & 0.54 & 0.74 & 0.14 & 0.59 & 0.28 \\
\hline 9 Shopping & 0.48 & 0.51 & 0.71 & 0.28 & 0.38 & 0.51 & 0.38 & 0.57 \\
\hline 10 Maintaining own health & 0.28 & 0.67 & 0.80 & 0.13 & 0.22 & 0.69 & 0.11 & 0.80 \\
\hline 11 Communication & 0.10 & 0.72 & 0.69 & 0.17 & 0.18 & 0.65 & 0.10 & 0.68 \\
\hline 12 Social interaction & 0.08 & 0.71 & 0.64 & 0.20 & 0.19 & 0.62 & 0.16 & 0.60 \\
\hline 13 Daily decision taking & 0.09 & 0.83 & 0.98 & -0.03 & 0.03 & 0.88 & 0.00 & 0.88 \\
\hline 14 Memory & -0.19 & 0.85 & 0.97 & -0.13 & -0.16 & 0.83 & -0.15 & 0.91 \\
\hline 15 Behavioural control & -0.15 & 0.57 & 0.83 & -0.09 & -0.14 & 0.68 & -0.04 & 0.64 \\
\hline
\end{tabular}

* Loadings $>0.40$ are marked with boldface

The existing literature is inconclusive as to whether disability, the home-dwelling elderly. ${ }^{[15-17]}$ Our findings show firstly, as expressed through ADL and IADL variables, represents the need for both home health and institutional care for the one, two or even more dimensions in describing needs for elderly can be described by using two factors; one containing 
variables related to physical disability, and one containing variables related to cognitive impairment. Thus factorization seems to be independent of whether care is provided at home or in nursing homes. Secondly, the distinction between the "younger elderly" (67-80), and the "older elderly" (80+) does not seem to be important when choosing neither the number of factors nor the variables contained in each factors. Thirdly, we find no systematic differences between men and women in the characterization of user needs. Thus both the number of factors and the variables contained in each factor seems to be the same for men and women. Others has found that more factors are needed to describe needs for females than males related to household activities. ${ }^{[21]}$ This difference could be related to different social structures between countries.

Table 8. Item parameter estimates of $\beta$ (standard error) from the 1PL model for home-dwelling elderly individuals and nursing home residents

\begin{tabular}{|c|c|c|c|}
\hline \multicolumn{2}{|l|}{ Home-dwelling elderly } & \multicolumn{2}{|l|}{ Nursing home residents } \\
\hline ADL/IADL/mobility & Item difficulty $(\beta)$ & ADL/IADL/mobility & Item difficulty $(\beta)$ \\
\hline Housekeeping & $3.78(0.11)$ & Housekeeping & $8.13(0.49)$ \\
\hline Shopping & $1.68(0.08)$ & Cooking & $6.92(0.33)$ \\
\hline Personal hygiene & $0.78(0.08)$ & Personal hygiene & $6.23(0.28)$ \\
\hline Outdoor mobility & $-0.04(0.08)$ & Outdoor mobility & $3.97(0.17)$ \\
\hline Cooking & $-0.07(0.08)$ & Dressing & $3.69(0.16)$ \\
\hline Dressing & $-0.84(0.08)$ & Toilet & $2.09(0.13)$ \\
\hline Toilet & $-2.76(0.09)$ & Indoor mobility & $1.02(0.11)$ \\
\hline Indoor mobility & $-3.00(0.10)$ & Eating & $-0.97(0.11)$ \\
\hline Eating & $-5.52(0.15)$ & & \\
\hline Cognitive & & $\underline{\text { Cognitive }}$ & \\
\hline Maintain own health & $2.80(0.09)$ & Maintain own health & $6.95(0.42)$ \\
\hline Social interaction & $-1.19(0.07)$ & Shopping & $5.96(0.29)$ \\
\hline Daily decisions making & $-1.74(0.08)$ & Daily decision making & $3.49(0.15)$ \\
\hline Memory & $-2.07(0.08)$ & Memory & $2.46(0.12)$ \\
\hline Communication & $-4.36(0.13)$ & Social interaction & $2.34(0.12)$ \\
\hline \multirow[t]{2}{*}{ Behavioural control } & $-4.94(0.15)$ & Communication & $-0.28(0.09)$ \\
\hline & & Behavioural control & $-0.52(0.09)$ \\
\hline$-2 * \log$ likelihood ADL/IADL 1PL & $18,451.2$ & $\begin{array}{l}-2 * \log \text { likelihood ADL/IADL } \\
1 \mathrm{PL}\end{array}$ & $5,558.0$ \\
\hline $\begin{array}{l}-2 * \log \text { likelihood } \\
\text { Cognitive } 1 \mathrm{PL}\end{array}$ & $11,140.4$ & $\begin{array}{l}-2 * \log \text { likelihood } \\
\text { Cognitive 1PL }\end{array}$ & $5,879.3$ \\
\hline
\end{tabular}

Our analysis supports previous studies that found that ADL and mobility variables constitute a common dimension in describing the service needs for the home-dwelling elderly and for nursing home residents, whereas the IADL variables could both be physical and cognitive depending on the recipients being analysed. ${ }^{[23-25]}$ Furthermore, our results indicate that behavioural problems can be grouped with other cognitive variables for elderly users. This finding is in contrast to others, who has found that aggressive behaviour could be treated as a separate dimension for nursing home residents. ${ }^{[52]}$ This further underscores the point that some IADL variables have a strong cognitive element. Thus, the distinction between physical and cognitive variables may be more relevant than that between ADL, IADL and cognitive vari- ables. This could explain why some variable as for instance shopping is a physical disability for some recipients while it appears as a cognitive dimension for others.

The IPLOS system contains 15 variables describing disability and cognitive impairment. Although other instruments will contain different variables, we still believe that our analyses suggest that a common factorization is applicable for the population $67+$. For policy makers this means that a common "case-mix system" based on this factorization can be developed for planning, financing and monitoring the use of long-term care services for this group.

We found that the hierarchical ranking of variables to be quite similar between home dwelling elderly and those living 
at nursing homes. There was one exception namely cooking which was considered as medium difficult for home dwelling elderly, while it emerged as the second most difficult task for those living in nursing homes. This is in contrast to others who found that cooking, unlike other tasks, was considered as less difficult in a nursing home setting than among home dwelling elderly. ${ }^{[53]}$ However, the level of difficulty for performing different tasks was generally higher for the elderly living in nursing homes. This result suggests that the transition from home care to nursing home care is attributable to a general worsening of disability more than to a sudden change in the capacity to perform specific tasks, and thus that setting (home vs institutional care) in our case is a proxy for severity. These findings are in accordance with others. ${ }^{[53]}$ Among home dwelling elderly there were small differences in gaps and no differences in hierarchical ranking stratified by gender or age (results not shown), which is in accordance with others. ${ }^{[26]}$

Large differences between the difficulty parameters of the variables studied highlight areas where the IPLOS system could have a low level of precision. When instruments show gaps between the least difficult variables, it becomes more difficult to separate between the least disabled individuals; conversely, gaps between the most difficult variables make it more difficult to distinguish between the most disabled persons. ${ }^{[14,30,54]}$ This scenario may be related to both the number and the types of variables included. ${ }^{[14]}$ For both groups of elderly, we found relatively large gaps at both ends of the physical disability measures. For the home-dwelling elderly, the difference between eating and indoor mobility was large, although we consider this to represent a minor problem. As shown in Table 1, approximately $96 \%$ of homedwelling elderly were capable of eating alone, and most of those living in nursing homes were also able to eat by themselves. For the home-dwelling elderly, the gap between housekeeping and shopping was more striking, as approximately $70 \%-90 \%$ of home-dwelling recipients required help with housekeeping or shopping. This large gap could make it more difficult to differentiate among the least disabled. Large gaps for the least and most disabled home-dwelling elderly persons have also been detected in studies using other instruments, suggesting that this problem is not specific to the IPLOS system. ${ }^{[29,55]}$ For patients in nursing homes, the gaps were large between the most difficult variables. The large gap between the most difficult variables-housekeeping, cooking, personal hygiene and outdoor mobility-could be related to the fact that the two first are IADL variables and that very few individuals actually need to perform these tasks in a nursing home setting. We found, in Table 1, that nearly $100 \%$ of those living in nursing homes required help with these tasks.

We also observed that there were relatively large gaps between the cognitive variables for the two groups of elderly individuals. Thus, the IPLOS system does not appear to be well suited for detecting differences between users with severe cognitive impairment. One possible solution, when there are gaps, could be to split the variable in question into multiple "sub"-variables, e.g., a possibility is to split indoor mobility into three separate variables. ${ }^{[21]}$ In a more general analysis 166 ADL/IADL variables were analysed and identified potential variables that could be included in disability instruments to reduce information gaps. ${ }^{[28]}$ After a variable is split, the system may be more capable of identifying differences between both the most and least severely disabled recipients.

In Norway today, a composite score of all 15 IPLOS variables is used to describe "severity". [56] However, our results show that this may lead to an inaccurate picture of both severity and the resulting need.

A strength of this study is that analysis are based on everyday use of a system that is mandatory. Thus, we also believe that results should be applicable in Norwegian long term care. There are, however, also some caveats in our approach. Firstly, the IPLOS system contains fewer variables than other frequently used instruments; in particular, it contains fewer IADL variables. Thus, frequently used IADL variables such as "handling money" and "using phone/internet" can be indirectly included in "shopping", and the variable "maintaining own health" has a broader definition than the frequently used IADL variable "responsibility for own medications". These variables have been reported in some studies to be included in a separate "cognitive" IADL dimension in addition to other "physical" IADL variables. In contrast, IPLOS includes variables related to cognitive and behavioural functioning, which enables us to test IADL variables against cognitive impairment. Further the IPLOS system does not have information of other potential determinants of need as e.g., medication and education. Secondly, the data analysed in this study were a specific Norwegian setting; therefore, we cannot confirm their representativeness for other settings. Thirdly, Although IPLOS, as other instruments, have gaps along the continuum, comparison with other instruments was not possible with the available data. Further research should compare IPLOS against other reliable instruments.

\section{Conclusion}

Factorization suggests that all elderly (67 years and older) long term care users can be adequately described along two dimensions; one reflecting physical disability and one re- 
flecting cognitive impairment. However both the number of factors and the variable contained in each factor is likely to depend on the instrument used to characterise LTC users.

The IRT analysis showed minor differences in the hierarchically structure between home dwelling elderly and nursing home residents. On the other hand IRT analysis revealed large information gaps between the different variables in the system currently used in Norway. Especially it seems less suited to discover differences in need among the less disabled home dwelling elderly. Thus, there is a need to supplement the design of the IPLOS system preferably with variables from other reliable instruments.

\section{ACKNOWLEDGEMENTS}

The study was conducted with grants from The Norwegian Association of Local and Regional Authorities (KS) and County Governor of Sør-Trøndelag.

\section{CONFLICTS OF INTEREST Disclosure}

The authors declare that there is no conflict of interest.

\section{REFERENCES}

[1] Kadushin G. Home health care utilization: a review of the research for social work. Health \& social work. 2004; 29(3): 219-244. http://dx.doi.org/10.1093/hsw/29.3.219

[2] Meinow B, Kåreholt I, Lagergren M. According to need? Predicting the amount of municipal home help allocated to elderly recipients in an urban area of Sweden. Health and Social Care in the Community. 2005; 13(4): 366-377. PMid:15969708 http: //dx.doi.org/10.1111/j.1365-2524.2005.00570.x

[3] Karlsson S, et al. Functional ability and health complaints among older people with a combination of public and informal care vs. public care only. Scandinavian Journal of Caring Sciences. 2008; 22(1): 136-148. PMid:18269433 http://dx.doi.org/10.1111/j.147 $1-6712.2007 .00549 . \mathrm{x}$

[4] Luppa M, et al. Prediction of institutionalization in the elderly. A systematic review. Age and Ageing. 2010; 39(1): 31-8. PMid:19934075 http://dx.doi.org/10.1093/ageing/afp202

[5] Døhl Ø, et al. Variations in levels of care between nursing home patients in a public health care system. BMC Health Services Research. 2014; 14(1): 108. PMid:24597468 http://dx.doi.org/10.1186 /1472-6963-14-108

[6] Katz S, et al. Studies of illness in the aged. The index of ADL: A standardized measure of biological and psychosocial function. JAMA. 1963; 185: 914-9. PMid:14044222 http://dx.doi.org/10.1001 /jama.1963.03060120024016

[7] Lawton MP, Brody EM. Assessment of older people: self-maintaining and instrumental activities of daily living. The Gerontologist. 1969; 9(3): 179-86. PMid:5349366 http://dx.doi.org/10.1093/ger ont/9.3_Part_1.179

[8] Mahoney FI, Barthel DW. Functional Evaluation: The Barthel Index. Maryland State Medical Journal. 1965; 14: 61-5. PMid:14258950

[9] Folstein MF, Folstein SE, McHugh PR. "Mini-mental state"-A practical method for grading the cognitive state of patients for the clinician. Journal of Psychiatric Research. 1975; 12(3): 189-98. http ://dx.doi.org/10.1016/0022-3956(75)90026-6

[10] Morris JN, et al. MDS Cognitive Performance Scale. Journal of Gerontology. 1994; 49(4): M174-82. PMid:8014392 http://dx.d oi.org/10.1093/geronj/49.4.M174

[11] Granger CV, et al. Advances in functional assessment for medical rehabilitation. Topics in Geriatric Rehabilitation. 1986; 1(3): 59-74. http://dx.doi.org/10.1097/00013614-198604000-00007

[12] Hebert R, Carrier R, Bilodeau A. The Functional Autonomy Measurement System (SMAF): description and validation of an instrument for the measurement of handicaps. Age and Ageing. 1988; 17(5): 293-302. http://dx.doi.org/10.1093/ageing/17.5.293

[13] Haley SM, et al. Activity Outcome Measurement for Postacute Care. Medical Care. 2004; 42(1): I-49. http://dx.doi.org/10.1097 /01.mlr.0000103520.43902.6c

[14] Haley SM, et al. Short-form activity measure for post-acute care Arch Phys Med Rehabil. 2004; 85(4): 649-60. http://dx.doi.o rg/10.1016/j.apmr.2003.08.098

[15] Norstrom T, Thorslund M. The structure of IADL and ADL measures: some findings from a Swedish study. Age and Ageing. 1991; 20(1): 23-8. PMid:2028846 http://dx.doi .org/10.1093/ageing/20 .1 .23

[16] Spector WD, Fleishman JA. Combining activities of daily living with instrumental activities of daily living to measure functional disability. J Gerontol B Psychol Sci Soc Sci. 1998; 53(1): S4657. PMid:9469179 http://dx.doi .org/10.1093/geronb/53B. 1.S46

[17] Thomas VS, Rockwood K, McDowell I. Multidimensionality in Instrumental and Basic Activities of Daily Living. Journal of Clinical Epidemiology. 1998; 51(4): 315-321. http://dx.doi.org/10.10 16/S0895-4356 (97)00292-8

[18] Chong DKH. Measurement of instrumental activities of daily living in stroke. Stroke. 1995; 26(6): 1119-1122. http://dx.doi.org/1 0.1161/01.STR.26.6.1119

[19] Lindeboom R, et al. Activities of daily living instruments Optimizing scales for neurologic assessments. Neurology. 2003; 60(5): 738742. http://dx.doi.org/10.1212/01. WNL.0000044402.163 15. FC

[20] Avlund K. Methodological challenges in measurements of functional ability in gerontological research. A review. Aging Clinical and Experimental Research. 1997; 9(3): 164-174. http://dx.doi.org/1 $0.1007 /$ BF03340145

[21] Cabrero-Garcia J, Lopez-Pina JA. Aggregated measures of functional disability in a nationally representative sample of disabled people: analysis of dimensionality according to gender and severity of disability. Quality of Life Research. 2008; 17(3): 425-36. PMid:18264797 http://dx.doi.org/10.1007/s11136-008-9313-x

[22] Linacre JM, et al. The structure and stability of the Functional Independence Measure. Arch Phys Med Rehabil. 1994; 75(2): 127-32. PMid:8311667

[23] Stineman MG, et al. Impairment-specific dimensions within the Functional Independence Measure. Arch Phys Med Rehabil. 1997; 78(6): 636-43. http://dx.doi.org/10.1016/S0003-9993(97 ) $90430-5$ 
[24] Ng TP, et al. Physical and Cognitive Domains of the Instrumental Activities of Daily Living: Validation in a Multiethnic Population of Asian Older Adults. The Journals of Gerontology Series A: Biological Sciences and Medical Sciences. 2006; 61(7): 726-735. http://dx.doi.org/10.1093/gerona/61.7.726

[25] Leung DYP, Leung AYM, Chi I. An Evaluation of the Factor Structure of the Instrumental Activities of Daily Living Involvement and Capacity Scales of the Minimum Data Set for Home Care for Elderly Chinese Community Dwellers in Hong Kong. Home Health Care Services Quarterly. 2011; 30(3): 147-159. PMid:21846228 http://dx.doi.org/10.1080/01621424.2011.592421

[26] Coster WJ, et al. Refining the conceptual basis for rehabilitation outcome measurement: personal care and instrumental activities domain. Medical Care. 2004; 42(1 Suppl): I62-72. http://dx.doi.org/1 $0.1097 / 01 . \mathrm{mlr} .0000103521 .84103 .21$

[27] Stephan A, et al. Validity, reliability, and feasibility of the German version of the Caregiver Reaction Assessment scale (G-CRA): a validation study. International Psychogeriatrics. 2013; 25(10): 16211628. PMid:23886344 http://dx.doi.org/10.1017/S104161 0213001178

[28] McHorney CA, Cohen AS. Equating Health Status Measures with Item Response Theory: Illustrations with Functional Status Items. Medical Care. 2000; 38(9): II43-II59. http://dx.doi.org/10. 1097/00005650-200009002-00008

[29] Fortinsky RH, et al. Measuring disability in Medicare home care patients: application of Rasch modeling to the outcome and assessment information set. Medical Care. 2003. 601-615 p.

[30] Fieo RA, et al. Calibrating ADL-IADL scales to improve measurement accuracy and to extend the disability construct into the preclinical range: a systematic review. BMC Geriatr. 2011; 11: 42. PMid:21846335 http://dx.doi.org/10.1186/1471-2 318-11-42

[31] Norwegian Directorate of Health, IPLOS veileder for personell i kommunale helse- og omsorgstjenester (In Norwegian). Oslo: Norwegian Directorate of Health. 2014.

[32] Ministry of Health and Care Services, St. meld. nr. 50 Handlingsplan for eldreomsorgen (1996-97) (In Norwegian). Oslo. 1997.

[33] Norwegian Directorate of Health, Individbasert pleie- og omsorgsstatistikk (IPLOS) i kostra - Forslag til informasjonssystem for pleie- og omsorgstjenesten (in Norwegian). Helsedirektoratet. 2000.

[34] Fries BE, et al. Refining a case-mix measure for nursing homes: Resource Utilization Groups (RUG-III). Medical Care. 1994; 32(7): 66885. http://dx.doi.org/10.1097/00005650-199407000-000 02

[35] WHO. International classification of impairments, disabilities and handicaps: A manual of classification retating to the consequences of clisease. Geneva: World Health Organization. 1980.

[36] Herbern SM, Grimeland MO. Hvordan benytter kommunene seg av og vedlikeholder IPLOS-dataene?-En unders $\varnothing$ kelse til norske kommuner (In Norwegian), ed. N.D.o. health. Oslo: Norwegian Directorate of Health. 2014.

[37] Trondheim Kommune, Rutiner ved registrering av ADL ferdigheter (unpublished) (In Norwegian). 2008.

[38] Watson R, Thompson DR. Use of factor analysis in Journal of Advanced Nursing: literature review. Journal of Advanced Nursing. 2006; 55(3): 330-341. PMid:16866827 http://dx.doi.org/10. $1111 / j .1365-2648.2006 .03915 . x$

[39] Holgado-Tello FP, et al. Polychoric versus Pearson correlations in exploratory and confirmatory factor analysis of ordinal variables.
Quality \& Quantity. 2010; 44(1): 153-166. http://dx.doi.org/1 $0.1007 / \mathrm{s} 11135-008-9190-\mathrm{y}$

[40] Kline R. Exploratory and Confirmatory Factor Analysis, in Applied Quantitative Analysis in the Social Sciences, Y. Petscher, C. Schatschneider, and D.L. Compton, Editors. Taylor and Francis: Hoboken. 2013.

[41] Gliem JA, Gliem RR. Calculating, interpreting, and reporting Cronbach's alpha reliability coefficient for Likert-type scales. Midwest Research-to-Practice Conference in Adult, Continuing, and Community Education. 2003. PMid: 12684791

[42] Mulaik SA. Foundations of factor analysis. Boca Raton, FL: Chapman \& Hall/CRC. XXIII. 2009.

[43] Thompson B. Exploratory and confirmatory factor analysis: understanding concepts and applications. Washington, DC: American Psychological Association. 2004. http://dx.doi.org/10.1037/1 0694-000

[44] Brown TA. Confirmatory factor analysis for applied research. New York: Guilford Press. XVIII. 2006.

[45] DeMars C. Item Response Theory. Oxford: Oxford University Press; 2010. http://dx.doi .org/10.1093/acprof : oso/9780 195377033.001.0001

[46] Bond TG, Fox CM. Applying the Rasch model: fundamental measurement in the human sciences. New York: Routledge. 2012.

[47] Wolfe F, Kong SX. Rasch analysis of the Western Ontario MacMaster questionnaire (WOMAC) in 2205 patients with osteoarthritis, rheumatoid arthritis, and fibromyalgia. Annals of the rheumatic diseases. 1999; 58(9): 563-568. PMid:10460190 http://dx.doi.o $\mathrm{rg} / 10.1136 /$ ard.58.9.563

[48] Jackson TR, et al. Validation of authentic performance assessment: a process suited for Rasch modeling. American Journal of Pharmaceutical Education. 2002; 66(3): 233-242.

[49] Coenders G, Saris WE. Categorization and measurement quality. The choice between Pearson and Polychoric correlations, in The multitrait-multimethod approach to evaluate measurement instruments, W.E. Saris and A. Münich, Editors. Budapest, Eötvös University Press; 1995. 125-144 p.

[50] Tabachnick BG, Fidell LS. Using multivariate statistics. Boston, Mass.: Allyn and Bacon. 2001. PMid:16705786

[51] Osborne JW, Costello AB, Kellow TJ. Best practices in exploratory factor analysis, in Best practices in quantitative methods, J.W. Osborne, Editor. Thousand Oaks, Calif: SAGE Publications; 2008.

[52] Sommer $\mathrm{OH}$, et al. Factor analysis of the brief agitation rating scale in a large sample of Norwegian nursing home patients. Dementia and Geriatric Cognitive disorders. 2010; 29(1): 55-60. PMid:20110701 http://dx.doi.org/10.1159/000265542

[53] Finlayson M, Mallinson T, Barbosa VM. Activities of daily living (ADL) and instrumental activities of daily living (IADL) items were stable over time in a longitudinal study on aging. J Clin Epidemiol. 2005; 58(4): 338-49. PMid:15862719 http://dx.doi.org/10. 1016/j.jclinepi.2004.10.008

[54] Lai SM, et al. Physical and social functioning after stroke: comparison of the Stroke Impact Scale and Short Form-36. Stroke. 2003; 34(2): 488-93. http://dx.doi.org/10.1161/01.STR.000005 4162.94998.CO

[55] Sheehan TJ, et al. Measuring disability: application of the Rasch model to activities of daily living (ADL/IADL). J Outcome Meas. 2001; 5(1): 839-63.

[56] Norwegian Directorate of Health, Anbefaling fra arbeidsgruppe revidering av IPLOS samlemål-Rapport fra arbeidsgruppe nedsatt av Helsedirektoratet. Oslo (in Norwegian): Helsedirektoratet. 2010. 